\title{
Redemocratização no Brasil: continuidade ou ruptura?
}

\author{
Redemocratization in Brazil: continuity or rupture? \\ Redemocratización en Brasil: ¿continuidad o ruptura?
}

Ana Cristina Augusto de Sousa*

Lays Correa da Silva**

Lemos, Renato. Ditadura, anistia e transição politica no Brasil (1964-1979). Rio de Janeiro: Consequência, 2018. 544p.

Em tempos em que proliferam disputas narrativas e versóes negacionistas a respeito da ditadura militar brasileira, a publicação do livro Ditadura, anistia e transição política no Brasil (1964-1979), do historiador Renato Lemos, chega em boa hora. Enquanto parte da população brasileira e políticos têm feito apologia do regime ditatorial, o autor expóe no livro o projeto daqueles que não agem assim por desconhecimento, mas sim por comprometimento com a face mais brutal da dominação burguesa no Brasil, como diz o professor Marcelo Badaró (UFF) no prefácio do livro.
Renato Lemos é professor titular de História do Brasil na Universidade Federal do Rio de Janeiro e coordena o Laboratório de Estudos sobre os Militares na Política $(\text { LEMP/UFRJ })^{1}$. O historiador marxista defende o uso da nomenclatura "ditadura empresarial-militar" para designar o regime de 1964-1985, no lugar de "ditadura militar", por entender que esta generaliza os militares, ao mesmo tempo em que oculta os vínculos de classe das lideranças civis beneficiadas pelo golpe.

O livro, adaptado de sua tese para progressão a professor titular do Instituto de História da UFRJ, é uma obra informativa e

\footnotetext{
${ }^{1}$ O laboratório possui um site que reúne a produção acadêmica tanto do historiador como de seus orientados e colaboradores do LEMP e pode ser acessado através do link: https://lemp.historia.ufrj.br/
}

DOI: http://dx.doi.org/10.1590/2237-101X02204713

Resenha recebida em 29 de abril de 2020 e aceita para publicação em 5 de agosto de 2020.

* Pesquisadora da Fundação Oswaldo Cruz, Escola Nacional de Saúde Pública e Professora de História do Instituto Federal de Educação, Ciência e Tecnologia do Rio de Janeiro (IFRJ), Rio de Janeiro/RJ - Brasil. E-mail: anacris.sousa@ensp.fiocruz.br. ORCID: https://orcid.org/0000-0002-5288-2274.

** Pesquisadora da Universidade Federal do Rio de Janeiro / Instituto de História, Rio de Janeiro/RJ - Brasil.

E-mail: layscorrea.s@gmail.com. ORCID: https://orcid.org/0000-0002-6664-4891. 
analítica sobre a campanha da anistia política no Brasil. Resultado de mais de uma década de pesquisa, teve a sua temática atualizada por ocasião da criação da Comissão Nacional da Verdade em 2011 para investigar as graves violaçôes de direitos humanos por agentes do Estado entre 1946 e 1988.

Entre as inúmeras fontes primárias consultadas, o autor utilizou arquivos privados, dentre os quais cabe destaque o do general Peri Constant Beviláqua. O militar foi um dos pioneiros do movimento pela anistia política depois do golpe e principal orador na cerimônia de lançamento do Comitê Brasileiro pela Anistia em 1978.

O objetivo principal do autor é entender a questão da anistia no Brasil pós-1964, a partir de uma narrativa que supere tanto a perspectiva liberal-democrática (anistia como "pacificação" dos brasileiros) - segundo ele, hegemônica nesse campo de estudos - quanto as que superestimam os efeitos da pressão dos movimentos populares sobre a abertura.

A perspectiva liberal-democrática se preocupa com a apuração de violaçóes de direitos humanos e a reparação simbólica e material das vítimas, defendendo a ideia de que providências jurídicas, políticas e educacionais teriam ação preventiva. Essa abordagem, simbolizada pelo bordão "Para que não se esqueça, para que nunca mais aconteça”, fomentou diversos estudos na área da Justiça de Transiçãa ${ }^{2}$. Por essa corrente,

\footnotetext{
${ }^{2}$ Sobre esse campo, que vem sendo constituído com um imenso aporte advindo sobretudo do Direito, achamos importante destacar as produçôes do International Center for Transitional Justice (ICTJ), que em 2011 publicou no Brasil, juntamente com a Comissão de Anistia do Ministério da Justiça, um
}

a anistia é comumente apresentada como uma forma de pacificaçáo encontrada pelas partes litigantes em prol da harmonia da sociedade. A segunda perspectiva, por sua vez, situada mais à esquerda no rol de interpretaçóes, descreve a anistia como uma vitória do chamado movimento popular da época, que teria forçado o recuo do autoritarismo e impulsionado a redemocratização (LEMOS, 2018, p. 18).

No livro, o autor não dialoga explicitamente com nenhuma dessas correntes, mas diverge de ambas, do ponto de vista historiográfico. Como alternativa, propõe o entendimento da Lei da Anistia (Lei no 6.683 de 1979) como resultado de uma operação política em que os dirigentes do regime capturaram da oposição a bandeira da anistia e a redefiniram de acordo com os seus objetivos estratégicos (p. 19).

A defesa dessa tese é apresentada em três capítulos. No primeiro, "Anistia: uma impossibilidade sistêmica: 1964-1974", o autor mostra como as doutrinas político-militares do período, baseadas fortemente na noção de "inimigo interno", acabaram limitando o movimento coletivo pela anistia a reivindicaçôes de caráter individual. Essa parte inclui resultados inéditos de pesquisa sobre a Doutrina de Guerra Revolucionária no Brasil, que teria tido um papel fundamental na orientação do regime ditatorial (p. 47).

O segundo capítulo, "A anistia e o projeto distensionista: 1974-1978", apresenta os

manual sobre o tema para a América Latina (REÁTEGUI, 2011), e as publicaçóes semestrais da $R e-$ vista Anistia durante os anos de 2009 até 2012, que podem ser consultadas através do site: http://memorialanistia.org.br/revista-anistia/. 
fundamentos da estratégia de transição política adotada pelos dirigentes do regime após 1974 e as táticas adotadas para alcançar o seu maior objetivo: um regime democrático restrito, baseado em maiorias parlamentares conservadoras. Nesse capítulo, o autor desvela as origens do projeto distensionista no Brasil, expondo a ligação de expoentes da ciência política norte-americana com intelectuais brasileiros ("conexão Harvard") na formulação de estratégias e táticas de transição do regime (p. 123).

O terceiro capítulo, "A anistia como tática do regime: 1979", trata dos primeiros cinco meses do governo do general Figueiredo (1979-1985) em que a anistia passa a ser reconhecida publicamente pelos dirigentes do regime até a sua aprovação final. Aqui, $o$ autor mostra como $o$ atendimento às conveniências táticas oficiais asfixiou a principal bandeira do movimento oposicionista: a concessão de uma anistia ampla, geral e irrestrita acompanhada da desarticulação do aparelho repressivo do regime, da apuração da autoria de crimes contra oposicionistas e da responsabilização de agentes de Estado comprovadamente responsável por eles. A anistia aprovada pelo governo náo foi ampla, nem geral, nem irrestrita. E, graças ao seu artigo sobre "crimes conexos", que viria a ser interpretado como uma garantia de reciprocidade na anistia, ainda contribuiu fortemente para o bloqueio de qualquer iniciativa de investigação e punição dos agentes do Estado acusados de violaçóes de direitos humanos.

A hipótese geral que orienta a obra é que o processo que levou à anistia política no
Brasil expressou duas tradiçôes mais abrangentes anteriores: a da conciliação como forma de preservaçáo dos interesses fundamentais das classes dominantes na nossa sociedade e a da contrarrevolução preventiva como estratégia anticrise (p. 18). Nesse sentido, o autor enquadra o tema na dinâmica e na cronologia do processo de contrarrevolução que estrutura politicamente a sociedade brasileira também (p. 26).

A partir de Florestan Fernandes (1979), o autor explica que a luta de classes no mundo naquele momento levou as classes dominantes brasileiras a adotar prioritariamente $\mathrm{o}$ que esse teórico denominou de "métodos de contrarrevoluçáo preventiva". Desse modo, o uso da repressão violenta teria sido um aspecto constitutivo e inerente à implantação e à reprodução do regime político contrarrevolucionário e não uma expressão da perversão particular dos agentes do regime, embora certamente isso tenha contado em determinadas situaçôes. A repressão violenta teve alvos precisos, ele nos lembra: as ligas camponesas e os sindicatos rurais no campo e as organizaçóes de trabalhadores e de estudantes, nas cidades, aos quais se somaram num segundo momento (AI-5) os militantes de organizaçóes armadas da esquerda (p. 85).

Assim, a violência política aberta e também os métodos de negociação democrática - nas figuras do Judiciário e do Parlamento - teriam uma racionalidade própria derivada das necessidades da classe dominante no exercício do poder, que deram sentido aos dispositivos jurídicos criados pela ditadura, como os atos institucionais e complementares, as constituiçóes outorgadas e outros 
diplomas legais, assim como aos subprodutos desse aparato autoritário: mortos, desaparecidos, presos políticos etc. Nas palavras do autor, "racionalidade essa que estaria na base, também, da evolução das leis que tipificaram o crime político no país e condicionaram o instituto da anistia" (p. 24).

$\mathrm{O}$ autor mostra ainda que, no desmonte do regime ditatorial e sua substituição por outro, qualquer passo em falso inviabilizaria uma "transição sem ruptura", ou, nas palavras do general Ernesto Geisel, uma "abertura lenta, gradual e segura”. O pré-requisito para o sucesso desta estratégia era a obtenção de consenso em torno da própria transição, que deveria estender sua legitimidade para além das camadas da sociedade que haviam apoiado o golpe. O tipo de anistia a ser concedida, ampla ou limitada, geral ou parcial, irrestrita ou condicional, resultaria, assim, do rumo escolhido pela classe dominante brasileira e do esvaziamento de qualquer potencial antissistêmico (p. 25).

É importante notar que a transição do regime, segundo o autor, não visava outro qualitativamente diferente, mas apenas uma outra forma que incorporasse as novas forças políticas, sob tutela militar. Os limites das reformas foram dados pelo caráter estritamente burguês da direção do processo político. O sentido básico da transição foi, assim, o "de preservar as condiçôes da dominação política de uma classe social absolutamente desprovida de vocaçáo transformadora" (p. 26).

A anistia de 1979 teria resultado, portanto, de um grande acordo entre setores dirigentes do regime militar e setores moderados da oposição, por iniciativa e sob o controle dos primeiros. Integraria também a agenda de transformaçôes buscadas desde 1973 por lideranças civis e militares do governo, tais como a ampliação do leque de opçóes partidárias e o abrandamento da legislação repressiva, entre outros (p. 26).

$\mathrm{O}$ autor destaca ainda que as ampliaçóes da lei de 1979, em especial, a instituiçáo da reparação financeira às vítimas da ditadura, podem ser entendidas como momentos do processo de despolitização do problema e vitória estratégica da direção burguesa no processo de transição política pós-1974 (p. 484). Entretanto, historiadores mais ligados aos estudos sobre Justiça de Transição vêm mostrando como os atores envolvidos nesse processo utilizaram o espaço aberto pela instituição da reparação financeira para disputar politicamente as narrativas sobre o período em um movimento conhecido como "virada hermenêutica" da Comissão da Anistia (GATHE, 2015; RODEGHERO, 2012).

Aliás, o pressuposto teórico que admite que os atores sejam capazes de tomar decisóes "estratégicas" pode ser um desafio a leitores que valorizem mais o peso de cisóes e disputas internas dos grupos de interesse nas escolhas políticas. Embora reconheça essas variáveis, o autor mira no resultado da ação coletiva que, para ele, é uma ação de classe (p. 476).

A pesquisa realizada por Renato Lemos constitui uma importante contribuiçáo para os estudos sobre transiçóes políticas. Uma das obras que mais influenciou as interpretaçóes latino-americanas sobre o tema foi o estudo de Guillermo O’Donnell, Philippe Schmitter e Lawrence Whitehead (1986), 
que comparou a transição de regimes autoritários de países europeus e latino-americanos. Os pesquisadores destacaram a "extraordinária incerteza" dos processos de transição democrática e identificaram um conjunto de variáveis que devem ser considerados para o estudo das transiçôes políticas negociadas ou por rupturas, como o papel dos atores políticos envolvidos na transição, a configuraçáo de pactos políticos e a realização de eleiçôes, entre outros (LIMA; SÁ, 2005, p. 132). A crítica sociológica dos anos 1990 indicou também a necessidade de examinar, para além da transição política, a relação entre Estado, instituiçôes políticas e sociedade civil (AVRITZER; COSTA, 2004). Nesse sentido, a democratizaçáo passou a ser reconhecida como um "processo permanente e nunca inteiramente acabado de concretização da soberania popular" (AVRITZER; COSTA, 2004, p. 704).

A obra aqui resenhada se insere numa linha de interpretação que põe em causa a efetividade dos processos de transiçôes políticas derivadas de negociaçóes, que o alinha a outros autores latino-americanos, como o chileno Tomás Moulian (1997), por exemplo. Tal linha busca explicitar, mais do que rupturas, as continuidades presentes, em termos estruturais, nos processos de transiçóes políticas. Nesse sentido, a transição política brasileira, negociada de cima para baixo, convida a refletir sobre uma democracia que, apesar das liberdades, manteve inalteradas do passado autoritário estruturas brutais de desigualdade social e repressão estatal do descontentamento popular.

Não resta dúvida que a maior contribuição do livro é oferecer uma interpretação singular e arrojada do processo político brasileiro recente, na qual ditadura, transição e democracia seriam faces de um mesmo padrão de dominação de classes, em que as mudanças de regime político foram usadas como "recursos conscientes" de setores empresariais e militares alinhados no mesmo projeto político.

\section{Referências}

AVRITZER, Leonardo; COSTA, Sérgio. Teoria crítica, democracia e esfera pública: concepções e usos na América Latina. Dados - Revista de Ciências Sociais, Rio de Janeiro, v. 47, n. 4, p. 703-728, 2004.

FERNANDES, Florestan. Apontamentos sobre a "teoria do autoritarismo". São Paulo: Hucitec, 1979.

GATHE, Glenda. A virada hermenêutica da Comissão de Anistia: a anistia brasileira e as diferentes estratégias de reparação (20072010). Dissertação (Mestrado em História Social). Programa de Pós-Graduação em História Social, Universidade Federal do Rio de Janeiro, Rio de Janeiro, 2015.

LEMOS, Renato. Ditadura, anistia $e$ transição política no Brasil (1964-1979). Rio de Janeiro: Consequência, 2018.

LIMA, Bernardo; SÁ, Tiago. As teorias da transição para a democracia e o caso português. Revista de Imprensa Internacional, p. 127-144, set. 2005.

MOULIAN, Tomás. Chile actual: anatomia de um mito. Chile: LOM-ARCIS, Ed. 5, 1997. 
O'DONNELL, Guillermo; SCHMITTER, RODEGHERO, Carla. Anistia, Philippe; WHITEHEAD, Lawrence. esquecimento, conciliação e reconciliaçáo: Transition from authoritarian rule. Prospects tensóes no tratamento da herança for democracy, 4 v. Baltimore: The Johns da ditadura no Brasil. In: ARAUJO, Hopkins University Press, 1986.

Maria; MONTENEGRO, Antonio; REÁTEGUI, Felix (org.). Justiça de transiçâa - manual para a América Latina. Brasílial RODEGHERO, Carla (orgs.). Marcas da memória: história oral da anistia no Brasil. Nova Iorque: Ministério da Justiça/ICTJ, Recife: Ed. Universitária da UFPE, 2012. 2011. p. $97-136$. 